\title{
Microeconomias afetivas e globais do forró na Península Ibérica
}

Ricardo Nascimento e Raul Ortega ${ }^{1}$

UNILAB, Ceará, Brasil e Università Politècnica de València, Espanha

\begin{abstract}
O forró é um gênero musical e performático, oriundo do meio rural da região Nordeste do Brasil, gênero que hoje se encontra difundido, no formato da dança e da música, em todo o mundo. Os contornos globais do seu crescimento envolvem uma economia cultural e afetiva particular, onde circuitos comerciais e não comerciais imbricam-se em relaçóes de sociabilidade, lazer e bem-estar. O objetivo deste artigo é compreender os meandros do processo de transnacionalização do forró, aspectos das suas dinâmicas econômicas, culturais e sociabilidades, com base em um estudo de caso e uma etnografia multisituada junto dos praticantes de forró nas cidades de Lisboa, em Portugal, e Valência, em Espanha.

Palavras-chave: economia cultural, globalização, forró, sociabilidade
\end{abstract}

\section{INTRODUÇÃO}

O forró é um gênero musical e performático, oriundo do Nordeste brasileiro, mas que hoje pode ser encontrado em qualquer parte do mundo, seja no seu formato musical ou aliado à prática da dança. Enquanto gênero musical, o forró apresenta-se como um estilo diversificado que, ao longo dos anos, se modificou tendo em conta as suas incursões no mercado fonográfico brasileiro e internacional. De acordo com Silva (2003), podem ser catalogados pelo menos três segmentos do forró: o forró tradicional, também conhecido como forró roots ou forró pé-de-serra, o forró universitário e o forró eletrônico ou forró pop.

À volta do vocábulo guarda-chuva forró reuniram-se, na sua origem, diversos ritmos musicais nordestinos, como prática social de ir dançar e consumir a música do Nordeste brasileiro. À

1 Ricardo Nascimento é professor do Instituto de Humanidades e Letras da Universidade da Integração Internacional e da Lusofonia Afro-brasileira. Contato: ricardonascimento@unilab.edu.br. Raul Ortega Moral é artista e doutorando do curso de Artes. Contato: signo@raulortegamoral.com. 
semelhança do forró, outros formatos musicais surgiram, como o samba, a lambada e o carimbó, que compactaram diferentes rítmicas locais. No tocante às culturas populares, estes gêneros musicais sempre tiveram forte ligação às práticas de sociabilidade das festas e danças. Ir para o forró, assim como ir para o samba, podia significar ir divertir-se, dançar e interagir com outras pessoas, assim como consumir música. Esta característica intrínseca do surgimento do forró, contida nas suas formas de sociabilidade, lazer e interação social, talvez possam, parcialmente, explicar o seu êxito transnacional.

A transnacionalização do forró, como de outras práticas culturais brasileiras, ainda estão muito pouco estudadas. No entanto, as pesquisas revelam que muitas destas performances têm origem na imigração brasileira dos anos oitenta e noventa, que, para além de possibilitar a difusão de ritmos dançantes como o forró, também cooperaram na expansão do maracatu, da capoeira e das religiões afro-brasileiras na Europa (Sarquis 2013; Cruz 2012; Nascimento 2015). Contudo, se as migrações dos brasileiros podem, em parte, explicar a expansão do fenômeno do forró, bem como de outros, caberá pensarmos que fatores locais proporcionaram uma maior inserção destas práticas no mercado, sua adesão, posterior produção cultural endógena e consumo, tanto da música como da dança.

Nosso estudo de caso demonstra que, em grande parte, o forró tradicional e universitário tem sido o mais apetecido pelo público europeu, frequentadores dos circuitos de forró por nós estudados, e que se auto designa de comunidade de "forrozeiros pé-de-serra". As particularidades desta comunidade remetem a um tipo de consumo peculiar em que as músicas, seus autores, suas histórias de vida, bem como o contexto cultural específico a que aludem, ganham significância simbólica, assim como a dança surge aliada ao consumo da música. $\mathrm{O}$ aprendizado do forró através da dança, é importante enfatizar, constitui o formato básico de adestramento físico, motor e auditivo do aprendiz, o elo que constitui o gosto pelo gênero musical, cuja aprendizagem se faz pelo corpo.

Partimos de uma etnografia multisituada, tal como sugere Marcus (1995), que propõe que se sigam as pessoas, as coisas, as metáforas, os enredos, histórias e alegorias, as biografias e os conflitos. No contexto de uma etnografia multisituada, Marcus (1995) salienta o conceito de mercadoria, que ao nosso ver se aplica ao forró como objeto de estudo num polo global. Para Marcus, o global não existe em si, mas emerge da relação entre os lugares, que no nosso estudo de caso se quer estabelecer entre Lisboa, Valência e a região Nordeste do Brasil, onde o ritmo do forró tem origem. Acresce a essa relação transnacional, o fato de que, muitos protagonistas imigrantes brasileiros produtores de forró na Europa são oriundos, principalmente, dos estados do Rio de Janeiro, São Paulo e Minas Gerais. Chama-nos a atenção para o fato de que as alegorias, metáforas e enredos descritos por Marcus (1995) podem tornar-se produtos, coisas, objetos vendáveis, sobretudo na sua forma de produção e consumo.

Este artigo parte de um estudo etnográfico, em que se privilegia a observação participante, junto dos grupos de frequentadores de aulas e concertos de forró, nas cidades de Lisboa, em Portugal e Valência, em Espanha. Temos por objetivo compreender os contextos transnacionais de crescimento, produção e circulação do forró, através do acompanhamento dos circuitos festivos do forró na Europa, bem como analisar as relações de sociabilidade estabelecidas entre os frequentadores de forró nesses locais. 
Como nós, os autores, chegamos a esta pesquisa sobre o forró? Aportamos a este tema através do interesse acadêmico por estudarmos os processos de transnacionalização de artefatos culturais com origem na cultura popular brasileira, caso principal da capoeira, objeto de pesquisa das nossas teses de doutorado. No entanto, ao longo do trabalho de campo, nos foram indicadas inúmeras pistas sobre a distribuição de outros bens culturais com origem no Brasil e que concerniam a processos migratórios de muitos brasileiros hoje residentes na Europa. Constatamos que os praticantes de capoeira brasileiros na Europa, terão sido responsáveis pelo desencadear de novos mercados culturais e de estilos de performances que, tendo estado vinculadas inicialmente ao mercado da capoeira, terão encontrado caminho autônomo para constituírem-se como prática de consumo cultural. Assim, ao partir da experiência acumulada no processo de transnacionalização da capoeira, os imigrantes brasileiros capoeiristas foram capazes de lançar mãos de outros elementos culturais, cujas potencialidades de consumo estariam a ser testadas, inicialmente, nos eventos e aulas de capoeira. O forró, o maracatu, o frevo, estavam nas bagagens de saberes destes imigrantes, algumas vezes de forma consistente, outras de forma incipiente. Ao longo dos processos migratórios, esses agentes foram capazes de mobilizar saberes, avaliar a conjuntura econômica dos países de residência, construir os gostos de um possível público, mobilizar e potencializar capitais que possuem ou que foram adquirindo, a fim de lançar-se em novos empreendimentos pessoais.

No âmbito desta pesquisa etnográfica, trazemos também a nossa participação pessoal nesta prática, o tempo que nela despendemos, a interlocução informal com uma vasta gama de atores que fazem parte dessa rede de mercado, a saber: os produtores, DJs, músicos, forrozeiros, dançarinos e professores de forró. No âmbito deste artigo, optamos por tratar alguns dos nossos interlocutores pelo nome, em particular, com os que mantivemos relações formais, é o caso dos nossos dois entrevistados, que serão apresentados adiante. Por uma questão de economia do artigo, os demais atores serão referenciados como agentes da rede de mercado do forró, que são muitos e com quem, na maioria dos casos, mantivemos apenas conversas informais de curta duração. Ao pensarmos uma microeconomia afetiva do forró, nos ocorreu que a comunidade de forrozeiros é uma construção social e que, em última instância, é construída a partir das representações, interpretações e sentidos que os próprios forrozeiros produzem de si, do forró e dos seus agentes. Como pesquisadores e partícipes das comunidades culturais que estudamos, pensamos ser coerente assumirmo-nos também como sujeitos da etnografia, porém, é de deixar claro que temos plena consciência do carácter construído deste espaço coletivo, da relevância das formulações idílicas, dos sentidos atribuídos ao forró e de suas formas de sociabilidade, como construtores da invenção de uma comunidade de consumo. Assim, de maneira deliberada, em alguns momentos e como provocação, adotamos a estratégia de deixar que as falas dos nossos interlocutores se confundam com as nossas e antever que, não é possível, de forma plena, fazer ciência e arte sem que em algum momento o sentimento de pertença e de gozo, que ambas propiciam, se evidencie com despojamento e naturalidade.

Henry Jenkins (2009) compreende que a economia afetiva seria uma estratégia de criação de vínculo entre os clientes e uma empresa, na busca de que os consumidores possam tornar-se aderentes e promotores de uma marca. $\mathrm{Na}$ nossa compreensão, existe, nas formas de consumo cultural criadas à volta das relações de sociabilidade estabelecidas entre os que vivenciam uma determinada prática cultural, o que concebemos por uma microeconomia afetiva. Esta microeconomia, que não é uma economia de consumo massificado e mercadológico ostensivo, pressupõe fatores como relações de proximidade, sentimentos, afeto, interação, trocas simbólicas e cooperativismo. Trata-se de uma vivência circunstanciada de consumo cultural, feita em grupos 
pequenos (ou não muito extensos) que, em alguns casos, podem se aglomerar em redes que se formam em torno de elementos afetivos presentes em momentos de sociabilidade e bem-estar. É importante enfatizar que a escala dessa microeconomia não tem por finalidade criar aderência a uma marca, mas sim a um prática cultural que se vivencia e é experienciada por relações afetivas e de sociabilidades definidas pelo grupo.

Lipovetsky e Serroy (2014) postulam que o momento atual da produção e reprodução do capitalismo move-se por dinâmicas que dão ênfase à estetização da vida cotidiana. Esta atualização do modelo de produção e consumo capitalista, para os autores, perspectiva-se por uma relação tripartida entre o estético, o imaginário e o emocional. Lipovetsky e Serroy (2014) reforçam ainda que o consumidor moderno global apresenta um desprendimento em relação às suas próprias referências culturais, o que se traduz num modo de consumo cultural eclético e de antropofagia da alteridade. O imaginário, na concepção desses autores, se efetiva a partir de uma inflação do estético, do controle dos sonhos, das utopias e das emoções. Segundo os autores, essa estetização ocupa o lugar do sagrado nas nossas sociedades, uma espécie de espiritualidade laica que rege as relações de sociabilidade, mediada pelo consumo de bens culturais. $\mathrm{Na}$ nossa compreensão, as formas de sociabilidade envolvidas pelo forró são construções sociais que têm como ponto de partida a estética do forró, assim como o seu imaginário e a dimensão emocional que o ato de "dançar forró" proporciona.

Simmel (2013) formula que a cultura pode ser um modo de consumação e plenitude dos seres humanos. Contudo, os artefatos culturais produzidos por esse desejo de consumação nem sempre são representados com o mesmo regime valorativo. O estatuto ontológico e estruturante da cultura para os seres humanos, como tal, é dado a partir das interações que os indivíduos estabelecem entre si e no acordo mais ou menos tácito sobre a relevância que um determinado artefato cultural adquire e como se torna imprescindível nas relações de sociabilidade. O que desejamos explicar é que, mesmo sendo um produto do mercado capitalista global, a relevância do consumo do forró, no campo das relações afetivas dos indivíduos, foi construída a partir de processos de consumação de necessidades básicas de sociabilidade dos grupos de indivíduos que se apropriaram da prática para fins que lhes são particulares. Assim sendo, não importa que outros tantos indivíduos, ao redor do mundo, estejam sendo atraídos pelo mercado da cultural global para "dançar forró", o que importa é o que esse artefato da cultura representa no âmbito pessoal da economia dos afetos e das relações sociais para cada indivíduo.

Para Blumer (1969), a ação conjunta dos indivíduos, tais como "dançar forró", é um ato social de produção de sentidos e ordenamento da realidade. $\mathrm{O}$ autor enfatiza que o ato social, como forma de ação coletiva, participa na produção de significados assim como uma vasta gama de tarefas, como o controle ou produção de emoções, a formação de identidades, o estabelecimento de papéis sociais e a negociação de conflitos, dentre outros. Em relação às emoções, o autor enfatiza que elas resultam da nossa participação na vida social e constituem-se como objetos sociais à medida que resultam das nossas interações com os outros indivíduos, em sociedade. Blumer também destaca que o processo de nomeação das emoções - por exemplo, "sinto-me feliz dançando forró" - permite dar significado ao sentimento de felicidade e afeto que se sente, ou propositadamente se produz no "ato de dançar forró".

A produção atual do forró comporta um vasto mercado europeu de circulação de profissionais, brasileiros e locais, a formação de bandas endógenas, circuitos de festivais e encontros, assim como de viagens ao Brasil. No caso Ibérico, a circulação desse gênero musical ganha 
contornos e particularidades, dada a ligação do forró aos contextos culturais de latinidade, que o aproxima a imaginários dos trópicos e de gêneros musicais cujos processos transnacionais foram anteriores ao forró, caso da salsa, do merengue e dos ritmos afro-cubanos. Será importante relembrar que a assimilação desses gêneros musicais pelo mercado comporta discursos de latinidades mestiças, narrativas multiculturalistas de junção de ritmos musicais oriundos de matrizes diferentes que, pelo menos no campo musical, compreenderam-se como complementares, mas que, nos processos de crioulização dos países de origem, fizeram-se por disputas sociais, fricções e subalternizações.

\section{DinÂmicas tRANSNACIONAIS dO FORRó}

Segundo Silva (2003), a origem do vocábulo forró encontra duas narrativas: uma na palavra forrobodó, que poderá ter origem nas línguas bantos e que significa festa, bagunça; e a segunda na palavra inglesa for all, que teria surgido por ocasião da implantação de caminhos de ferro pelos ingleses no Nordeste brasileiro, nos finais do século XIX. Eles organizavam festas abertas, com cartaz afixado, com as palavras inglesas for all, aberto a todos. No seu formato dançado, o forró surge como adaptação das danças de salão da Europa, e os seus desdobramentos atuais forjaram novos arranjos estéticos, com a introdução de passos de outras danças latinas.

Grosso modo, o forró tradicional - mais apetecido entre os jovens europeus dos circuitos que pesquisamos - remete às origens do forró, seus cantores e intérpretes no Nordeste brasileiro, e ao imaginário ligado ao mundo rural, à figura do cangaceiro, do vaqueiro, da aboiada e das músicas ao improviso dos repentistas nordestinos ${ }^{2}$. É a partir deste imaginário que emergem e ganham força os segmentos do forró que se seguiram ao estilo tradicional.

O forró universitário, por exemplo, surge com o crescimento do forró nos grandes centros urbanos brasileiros, no sul do país, e a sua apropriação pela classe média urbana. A partir da sua construção mercadológica como fato da vida urbana, o seu processo de exportação torna-se facilitado e o seu consumo inteligível a qualquer contexto social, cultural e econômico. $\mathrm{O}$ forró pé-de-serra e o forró universitário são dois formatos muito próximos e suas constituições passaram por renovações da linguagem musical, em que são introduzidos novos instrumentos musicais, mantendo a base instrumental tradicional. Acentua-se o campo melódico da música, ao mesmo tempo que a sua marcação rítmica se fortalece, favorecendo a aliança com a dança. Segundo Sarquis (2013), em consulta aos cantores de forró, o forró não se constitui como um ritmo, mas sim como uma forma de sociabilidade, um acontecimento festivo em torno da dança e do consumo musical, que envolve os ritmos do Nordeste brasileiro como o baião, o xote e o xaxado, consagrados nas canções do cantor nordestino Luiz Gonzaga. Em alguns autores, como Tinhorão (1998), existe uma compreensão da música brasileira, caso do forró, a partir de uma visão freiriana da democracia racial brasileira, com a junção das matrizes do negro, do índio e do branco europeu. Isto se traduz, por exemplo, na compreensão do formato musical dos instrumentos do forró, tais como: a sanfona, prima do acordeão português, a zabumba, tida como instrumento africano, o triângulo (ferrinhos), também de origem portuguesa e o pífano, de origem indígena. A relação com essas matrizes não é casual e a compreensão do forró como

2 Os principais nomes do forró tradicional são: Luiz Gonzaga, Jakson do Pandeiro, Carmélia Alves, Marinês, Abdias, Anastácia, Dominguinhos, Osvaldinho do Acordeom, Trio Nordestino, Trio Juazeiro, Os Três do Nordeste, Zé Calixto, Sivuca, entre outros. 
prática cultural também incorpora valores do discurso de harmonia racial e de sociabilidades multiculturais, que estão na base do consumo do forró transnacional. Dessa forma, é importante pensar que o forró, nesse contexto, constitui-se como uma categoria que articula e transversaliza identidades, sociabilidades, referenciais de consumo e estilos de vida. A recepção e interpretação de bens culturais no contexto transnacional, muitas vezes, necessitam de precedentes culturais de referência local que facilitem a sua tradução e consumo. No caso do forró, estamos a falar de um ritmo dançante, muito comum nas festas juninas do Nordeste brasileiro, de celebração dos santos católicos e que possui correspondência histórica nas festividades dos santos na Península Ibérica, em que ocorre o consumo de música popular ligeira. Para além disso, acreditamos que o sucesso anterior de alguns ritmos latinos, como a salsa e o merengue, tenham influenciado o interesse pelo consumo do forró, bem como a sua inteligibilidade enquanto ritmo dançante.

Sarquis (2013) acredita que o forró, no contexto europeu, também apropriado pelos dançarinos de danças latinas e africanas, proporcionou a anexação de novos gestuais de danças como a salsa, o merengue e a quizomba. Acresce a esses fatores o fato do forró ser consumido em um contexto urbano, espaço que também proporcionará o surgimento do forró universitário e que foi buscar suas influências à fusão de linguagens e atributos da música urbana como o rock e o pop. O sucesso e a vestimenta mercadológica de alguns ritmos brasileiros já consagrados internacionalmente, como o samba, a lambada, o axé music afro-baiano, também serviram de suporte para o empreendimento transnacional do forró.

Atualmente, quase todas as capitais europeias possuem circuitos festivos de forró, das quais se destacam as cidades de Lisboa, Barcelona, Berlim, Paris e Londres. Em diálogo com os DJs, músicos e frequentadores desses circuitos, constatamos que, de fato, o forró universitário e pé-de-serra figuram como consumo predominante no leque de estilos de forró e as razões por eles apontadas para esta predominância são de vária ordem.

Muitos integrantes das redes de produção do forró destacam o fato de que a organização dos circuitos de danças exclusivos de forró, para o público europeu, fez-se com base na chegada de imigrantes brasileiros, num primeiro momento praticantes de capoeira, que adiante passaram a ensinar esse formato musical, ou que dele se apropriaram como forma de encontrar subsistência econômica. Enfatizam ainda que, entre esses profissionais, o forró pé-de-serra e o universitário teriam sido os segmentos musicais do forró utilizados nos estúdios de ensino, razão que parcialmente explica a formação de um gosto musical específico. Posteriormente, todos os circuitos festivos, bem como de formação de bandas locais, foram constituídos à volta do gosto estabelecido entre esses pequenos grupos. O diálogo com os DJs, músicos e dançarinos do forró nos permitiu constatar que o formato dos circuitos festivos do forró são sistematicamente pensados, à medida que ocorrem, em interlocução com os DJs e bandas locais, sobre as necessárias reconfigurações do mercado. Com o crescimento e a frequência desses circuitos, os tipos de consumidores e suas necessidades, pensou-se que seria interessante manter um modelo comercial pequeno, intimista e de criação de um clima de familiaridade e proximidade. Os frequentadores, produtores, bandas e DJs locais acreditam que o forró universitário e o pé-de-serra, favorecem esse tipo de sociabilidade baseada na sensualidade e na alegria.

Trotta e Monteiro (2008) formulam que, no caso brasileiro, o consumo festivo do forró eletrônico, por parte dos jovens, tem representado a formação de um novo mercado musical mainstream. Este mercado, segundo os autores, tem como base as relações de sociabilidade, baseadas no encontro sócio-musical, assentes no trinômio festa, amor e sexo, e constituem o 
alicerce de uma nova forma de consumo e experiência social da música. A partir da perspectiva de Bourdieu (2007), uma cultura legítima afirma-se pela primazia da forma sobre a função. No caso do forró eletrônico, o alcance mercadológico deste segmento faz-se, segundo Trotta e Monteiro (2008), com base na razão inversa em que, não importando tanto a estética do forró, o que vale são as relações de sociabilidade que ele proporciona.

No caso europeu, os jovens consumidores de forró, por nós estudados em seus circuitos, enfatizam a necessidade de um equilíbrio entre a forma e a função. Assim, com a progressiva descodificação das letras da música na sua relação com as componentes melódicas, foi possível diferenciar os segmentos do forró por eles adotados do forró eletrônico, cujo conteúdo thes parece vazio e despropositado. Isso não quer dizer que o forró eletrônico tenha sido alijado do mercado europeu, pelo contrário, bandas como Gavióes do Forró ou Wesley Safadão movimentam-se no circuito comercial com relativo sucesso. No entanto, constatamos que, nestas performances, predomina o público de imigrantes brasileiros que, antes da sua chegada à Europa, tinham o segmento do forró eletrônico como parte do seu gosto musical. Os professores de forró atuantes na Europa, referem que o público europeu sente a necessidade de compreender o contexto musical que lhes serve de base como "música para ouvir e dançar" e, como tal, isto gera um gosto circunstanciado. Esses mesmos protagonistas enumeram ainda que, nos circuitos dançantes do forró ${ }^{3}$ que referimos, a festa é apenas parte do pacote mercadológico do evento, que compreende aulas de dança, consumo de comida brasileira, diálogo com os músicos e DJs, outras apresentações musicais brasileiras, venda de DVDs e CDs de bandas locais, o que não ocorre nas apresentações de bandas consagradas no Brasil, que apenas se apresentam e vão embora. Acrescentam ainda que, à semelhança de outros movimentos de discotecagem, também nos circuitos do forró valoriza-se o uso de dispositivos como o vinil.

\section{Entre Lisboa e Valência: o forró na Península Ibérica}

No ano de 2015, um artigo do periódico português Diário de Notícias, sobre o crescimento do forró em Lisboa, fazia a seguinte referência:

Há uma música doce no ar. Se não fosse o forró, que seria de mim Deus meu, que seria de mim”, canta a voz nas colunas de som, junto ao quiosque, na Avenida da Liberdade. É uma música gostosa, tropical, que convida à dança, e os pares, rapazes e raparigas que foram chegando aos poucos, rodopiam na calçada, de sorriso no rosto. A noite está morna e o baile ainda agora começou, há de prolongar-se até à meia-noite e, para quem passa, é uma boa surpresa. Há turistas que param a contemplar a cena, muitos puxam do telemóvel e fotografam, fazem vídeos. Há quem entre na dança, talvez viesse já com essa ideia, porque estes bailes de rua são agora frequentes em Lisboa. (Diário de Notícias, 15 de agosto de 2015) ${ }^{4}$

Um dos responsáveis por esse crescimento é André Luiz Maciel, nascido na cidade do Recife, capital do estado de Pernambuco, que chegou a Portugal por volta do ano dois mil. Mestre de capoeira, dançarino de frevo e forró, batuqueiro dos grupos de maracatu, Mestre ET, como é conhecido pelos brasileiros, criou em Lisboa, no ano de 2003, o Centro Cultural Arte

3 https://forrozinfreiburg.de/. O blog Forró in Freiburg nos fornece uma lista bastante significativa de festivais em toda a Europa e noutras partes do mundo. Numa visita virtual a estes festivais, alguns deles por nós bastante conhecidos, foi possível constatar o que os nosso interlocutores nos têm afirmado, a predominância do forró tradicional, em detrimento de outros formatos.

4 http://www.dn.pt/portugal/interior/lisboa-danca-na-rua-e-giro-e-nao-se-paga-4730715.html 
Pura, hoje situado no Bairro Alto. André Luiz nos indica que nasceu numa família de forrozeiros e que, aos oito anos, foi praticar capoeira. Já adulto e tendo feito parte de companhias de dança, foi morar em Brasília quando iniciou sua primeira experiência com aulas de forró. $\mathrm{O}$ centro cultural fundado por Mestre ET oferece uma vasta gama de aulas onde se pode aprender a capoeira, o samba, o forró e onde ensaia o grupo de maracatu Nação Arte Pura. Por se tratar de um local de grande circulação turística, já próximo da Praça de Luís de Camões, o grupo faz grande parte da sua divulgação em inglês, voltada para o púbico de turistas, bem como aos europeus que residem na cidade. André Luiz nos explica que a abertura do seu centro cultural culminou com a criação do projeto Forró Feliz que, em finais de 2017, possui núcleos nas cidades de: Graz, na Áustria, Santander, em Espanha, Londres, no Reino Unido, Budapeste, na Hungria, Nova York, nos Estados Unidos e em Lisboa. Segundo esse forrozeiro e promotor da atividade, existem na Europa bem mais de sessenta festivais de forró, tendo ele mesmo circulado com suas oficinas em quase todos eles. Mestre ET acredita que Lisboa é hoje a capital do Forró e que assim se tornou por vários fatores, sendo um deles o fato de que concentra parte significativa da imigração brasileira e de ser um dos poucos espaços europeus onde se pode praticar a língua portuguesa. Para muitos adeptos europeus de forró com quem tivemos contato, praticantes de capoeira, maracatu ou frevo ${ }^{5}$, entusiastas da cultura brasileira, Lisboa é representada como uma urbe que incorpora uma certa tropicalidade lusófona, que se verifica na sua oferta cultural, na presença massiva de imigrantes brasileiros e africanos, na arquitetura, que lembra cidades como Luanda ou Salvador, em aspectos físicos como a luminosidade, a temperatura mais elevada ao longo do ano, o recorte litorâneo do Atlântico e num espírito de tolerância cultural e mestiçagem, fabricado pela indústria turística e a propaganda do Estado.

Do ponto de vista financeiro, Mestre ET elucida que foi sempre muito bem sucedido com o forró. Segundo ele, seu centro, que funcionou até 2017, no Bairro Alto, foi sempre rentável e funcionava toda a semana, inclusive aos domingos. Segundo os seus cálculos, as aulas semanais, que ocorriam pela manhã, tarde e noite, davam-lhe uma renda mensal entre 1800 a 2100 euros, apenas com aulas de forró. Aos finais de semana, em eventos europeus de 3 dias, seu cachê habitual teria o valor fixo de 500 euros, sendo que ocorriam, pelo menos de uma a duas vezes por mês. O mestre acrescenta que possuía cerca de 102 alunos, com a circulação de 8 a 15 casais por aula, repartidos entre os vários dias e horários e que nos anos de existência do centro cultural em Lisboa recebeu à volta de 9000 pessoas. As aulas possuíam uma duração de uma hora e quinze minutos e o pagamento por aula incluía uma bebida, que podia ser uma cerveja, água ou caipirinha. Grande parte do seu público era rotativo, uma vez que tendo firmado parceria com centros de hotelaria local, recebia inúmeros turistas de várias partes da Europa e do mundo. O valor da aula era de 20 euros, sendo que 15 ficavam para o centro e 5 para as unidades hoteleiras. Tanto em Lisboa, quanto noutras partes da Europa onde circulou, nos conta o mestre que o público é de jovens e adultos, na sua maioria profissionais com algum tipo de formação e trabalho fixo, predominando em número maior as mulheres.

Mestre ET é um dos, entre outros tantos brasileiros, que hoje faz parte do ensino de forró em Lisboa. A sua história de imigração para a Europa, que é anterior à vinda para Portugal, fez-se pela busca de melhores condições de vida, mas principalmente por circunstâncias de um investimento em um mercado cultural crescente nos anos oitenta e noventa, o mercado de consumo de práticas culturais dos trópicos. Já nas décadas de setenta e oitenta incursionavam pela

5 Para além dos vários festivais de forró organizados na cidade, ela também recebeu os primeiros encontros europeus de maracatu e, em 2017, o primeiro encontro europeu de passistas do frevo. 
Europa e outros continentes os grupos brasileiros Viva Babia e Brasil Tropical, com uma grande trupe de dançarinos e percussionistas, profissionais, levando a cultura popular brasileira a vários locais do mundo (Nascimento 2015).

Será importante enfatizar que os processos transnacionais de chegada do forró, assim como da capoeira, do maracatu ou do samba, fazem parte de um movimento global, mais amplo, em que se insere, por exemplo, a chegada da quizomba e do kuduro - danças de origem angolana - nos anos noventa em Portugal. Recordamos que em 1996 nasce o Festival Andanças, festival de danças, em Portugal, consagrado à difusão das danças populares de várias partes do mundo, onde se pode aprender a dançar com música ao vivo e onde o forró tem cadeira cativa.

Inicialmente, Mestre ET começou a circular pela Europa com aulas e oficinas de capoeira. Com o passar do tempo, também nos circuitos de ensino da capoeira, passou a inserir aulas de frevo e forró que, anos mais tarde, criaram seus circuitos próprios de consumo. Segundo alguns dos intervenientes nesses circuitos, eles foram criados a partir de Lisboa que, no continente europeu, tornou-se uma das capitais do forró. Esse crescimento comercial gerou a formação de bandas locais, que hoje fazem sucesso inclusive no Brasil e, mais ainda, formou uma série de novos profissionais europeus, engajados no ensino e divulgação do forró. O contexto da crise econômica, do desemprego de jovens licenciados, da busca por outras formas de rendimentos, bem como do interesse pelo cosmopolitismo associado a estas práticas, fez com que muitos jovens europeus se interessassem por aprender e ensinar o forró, disputando, dessa forma, o mesmo mercado com os imigrantes brasileiros.

Os grandes polos de forró em Portugal são as cidades de Porto, Lisboa e Coimbra. A incidência de jovens universitários nestas cidades faz com que o gosto pelo forró universitário, bastante apreciado ao lado do forró tradicional, não seja mera coincidência. $\mathrm{O}$ crescimento do forró fez avançar, em Lisboa, um vasto mercado de festivais, aulas e espaços de danças, tendo sido criada inclusive a Associação Portuguesa de Forró, responsável pela divulgação e difusão da prática. Para além do Centro Cultural Arte Pura e da Associação Portuguesa de Forró, existem outros projetos como o Forró do Pablito, O Forró Para Todos e o Forró de Lampião, entre outros.

Muito embora o forró universitário e o forró pé-de-serra possam ter conquistado espaço entre os ouvintes e dançantes, outros estilos musicais de forró seguem ativos nas pistas de dança e no mercado de contratações de bandas. No entanto, muitos dos nossos entrevistados destacam que o forró universitário e o pé-de-serra, além de constituírem "música para dançar", são perfeitamente audíveis no contexto exterior à dança, sendo assim também "música para ouvir”. Destacamos que a constituição de gostos musicais pode, sim, seguir tendências lançadas pelo mercado, mas fazem parte, principalmente, de processos de agencialidade e escolha dos dançantes que, entre as possibilidades postas, são capazes de escolher e depurar, com cautela, as suas preferências musicais para ouvir e dançar. Ou seja, os gostos musicais constituem-se como construções sociais, individuais ou coletivas, cujas escolhas e seus processos decisórios funcionam como marcadores de legitimidade musical entre os grupos.

A banda Luso Baião, nascida em 2013, reúne músicos brasileiros e portugueses. O seu repertório é composto por músicas que são clássicos do forró, mas também de um cancioneiro português, em que se inclui nomes como Sérgio Godinho e Rão Kyau e, para além do forró, podem ser encontrados ritmos portugueses como o fado. $\mathrm{O}$ seu sucesso, incialmente circunscrito a Portugal, ganhou o mundo. O grupo participa em apresentações em várias partes da Europa 
e, no Brasil, encontra-se entre os grupos de sucesso nacional. Regra geral, no mercado musical brasileiro, é muito pouco usual consumir-se música brasileira feita fora do Brasil, tendo apenas poucos casos de sucesso. Assim, é interessante verificar como um produto cultural como o forró, através de processos de circularidade global, retorna, renovado, para ser bem-sucedido no Brasil.

Segundo os forrozeiros, produtores, dançarinos e professores, o movimento de arranque do forró, em toda a Europa, surge com os irmãos Pasqualini, praticantes de capoeira, oriundos do estado de São Paulo, que na Alemanha iniciaram o primeiro festival de forró na Europa, com cerca de dez anos de existência. Possuem o projeto Forró de Domingo, com bailes frequentes, e mantêm a escola Dança Bonito, na cidade de Stuttgart. Muitos forrozeiros apontam este espaço como o marco zero do mercado de festivais de forró na Europa, cujo modelo inicial é utilizado em vários outros.

Um levantamento fornecido por André Luiz, nos indicou que grande parte dos professores de forró são oriundos do eixo Rio de Janeiro, São Paulo e Minas Gerais, o que se explica pelo fato destes estados terem sido o berço do forró universitário e onde se encontram os principais festivais deste estilo. É importante salientar que a origem geográfica dos professores brasileiros pode determinar os estilos de dança do forró, tais como: o estilo cabroeira da Bahia, o estilo roots de Minas Gerais, o estilo Ituanas do Espírito Santo e o estilo universitário de São Paulo. Mestre ET nos explica que a diferença entre os estilos concerne ao gestual utilizado na dança, o repertório musical utilizado na aula mas também a proximidade dos pares na dança.

Rodrigo César Menezes é o promotor do forró na cidade de Valência. Nasceu em Vitória, no estado do Espírito Santo, mas cresceu em Belo Horizonte, Minas Gerais e chegou a Valência pela primeira vez em 2005. Escolheu a cidade como destino, guiado pelas referências de que era um lugar tranquilo, com praia e bom clima. No contexto social da época, o ano de 2004 foi o ano de chegada ao poder do PSOE (Partido Socialista Obrero Español) e também um ano de estabilidade econômica e política, favorecendo o desenvolvimento de políticas progressistas, como as regularizações massivas de imigrantes. Rodrigo Menezes tem hoje 42 anos e trabalha como comercial numa empresa de móveis em Alboraya, em Valência. Desde os 14 anos tem trabalhado no setor comercial de vendas. Ao terminar o $2 .^{\circ}$ grau científico, dedicou a sua formação como profissional no setor comercial. O seu pai foi trabalhador numa empresa de telecomunicações até à sua aposentadoria e a sua mãe trabalha em casa, sem remuneração econômica.

Rodrigo começa a dançar forró em 1990, com 24 anos de idade e antes já tinha praticado capoeira num grupo de capoeira Angola, o qual teve de abandonar por conta de um problema no joelho. Segundo Rodrigo, a sua chegada ao forró faz-se pela procura de um novo grupo social, um espaço onde se pudesse sentir incluído. Ele nos indica que aprendeu a dançar nas festas e nunca foi a uma aula de forró.

Rodrigo veio para Valência para viver com a sua companheira, também parceira na dupla de forró, e tendo encontrado dificuldades para sustentar a sua economia familiar, resolveu dedicar-se a outras atividades, acabando por se separar da sua parceira de dança e companheira.

Chegamos com a intenção de oferecer aulas de forró e tentar trazer essa cultura de musicalidade e dança em Valência, mas por motivos de adaptação e sobrevivência tive que procurar trabalho por outros caminhos e quando começou a piorar a relação pessoal com minha namorada e parceira de dança, acabou. Assim deixei de lado o projeto. (Entrevista com Rodrigo Menezes, 2017) 
Em 2008 explode a crise econômica na Espanha. O PSOE enfrentou, na sua segunda legislatura (2008-2012), uma série de problemas que acabariam com a sua capacidade de governar, como a bolha imobiliária, a crise bancária de 2010 e o drástico aumento do desemprego no fim da legislatura.

Por causa dos efeitos da crise, em 2012, Rodrigo decide voltar para o Brasil. No entanto, três anos depois, em 2015, desencantado com as condições de vida do Brasil, volta a Valência com a determinação de tentar novamente o projeto de difusão do forró.

A crise em 2012 fez que eu voltasse ao Brasil por causa do trabalho e o que me fez voltar a Valência foi a violência e elevado custo de vida no Brasil. Cheguei em fevereiro de 2015. Desta vez, voltei mais maduro, mais preparado e sabendo todas as dificuldades que teria que passar e o mais importante, sem pressa de obter resultados. E a chave estaria em encontrar pessoas para somar ao projeto. (Entrevista com Rodrigo Menezes, 2017)

Embora o retorno de Rodrigo não se faça com recurso a um capital econômico, fá-lo com um capital cultural que envolve saberes, símbolos e linguagens. Sobre esta riqueza de conhecimentos, Michael Hardt e Antonio Negri afirmam que:

Frequentemente o emigrante viaja com as mãos vazias e em condições de pobreza extrema, mas mesmo assim viaja com infinidade de conhecimentos, idiomas, habilidades e capacidades criativas: Cada imigrante traz consigo um mundo. (Michael Hardt e Antonio Negri 2004: 65)

Rodrigo traz uma bagagem cheia dos saberes e narrativas do forró, estes bens imateriais são os que lhe permitiram ressignificar a sua posição de imigrante entre os seus círculos sociais. No seu relato, Rodrigo diz que o projeto necessitou de pessoas para somar. O trabalho necessário para transmitir a cultura musical e de dança do forró é um trabalho coletivo, que se faz cooperativamente, para o qual o ato social de interação e contato é indispensável, e Rodrigo é sensível a esse fato.

Em junho de 2015, o projeto cultural Fusionart Multiespacio anunciava uma exibição de forró, a "salsa brasileira", no bairro de Benimaclet, organizada por Rodrigo. A exibição era parte da noite brasileira, na qual também havia comida, a preços populares, e música brasileira. Fusionart é um espaço cultural conhecido em Benimaclet, bairro onde moram universitários e a classe trabalhadora, com um passado histórico de associativismo cidadão e ligado ao ativismo de esquerda. A oferta cultural do Fusionart se caracteriza pela multiculturalidade dos seus eventos: noite cubana, noite jamaicana, noite argentina, noite africana e noite brasileira. Depois da primeira exibição de forró, em junho de 2015, o forró começa a fazer parte da oferta cultural do bairro de Benimaclet.

Nos primeiros meses no Fusionart, Rodrigo decidiu abrir um segundo horário, às terças-feiras. Como o Fusionart não tinha disponibilidade, procurou outro espaço no bairro, a Escuela Meme, um projeto colegiado onde funciona uma assembleia, na qual são tomadas decisões conjuntas e onde se procura a responsabilização horizontal e cooperativa dos agentes culturais que colaboram. A escola tem como objetivo a recuperação de ofícios e a produção cultural como elemento de construção comunitária. Para Rodrigo, a Escuela Meme é um modelo de projeto onde o forró se ajusta na perfeição, pelo espírito de comunidade e de autogestão.

Os sentidos atribuídos às aulas de forró estão para além da obtenção de rendimentos econômicos. A prioridade é facilitar a possibilidade de que as pessoas venham dançar, fazendo com 
que elas se vinculem e construam uma comunidade que possa manter as festas. O objetivo é promover um tipo de sociabilidade na qual o centro é a produção e o cuidado da comunidade, mediante a dança e o encontro festivo. Para a maioria dos participantes, este modelo de sociabilidade constitui traços de um estilo de vida alternativo à lógica do individualismo capitalista, uma vez que se prioriza a partilha da experiência do forró, em coletivo, frente à rentabilidade econômica. Claro que existe um lucro econômico e há uma preocupação em que o tempo despendido nas aulas seja rentável e garanta sustentabilidade ao proponente. No entanto, no projeto concebido por Rodrigo, o dinheiro aparece como um meio, não como um fim.

A aulas são um mote para se juntar uma pequena comunidade de pessoas que gostam de forró e que se propôs chamar oficialmente de Forró Valência, enquanto identidade coletiva desta comunidade. Foi então criada uma logomarca, como estratégia para chamar novos alunos, ganhar visibilidade nas redes sociais e para se conectar com outras comunidades de forró de Espanha e na Europa. Será valioso destacar, neste ponto, a importância da "música para ouvir e dançar" como suporte das interações entre o grupo e como elemento chave de compreensão das microeconomias afetivas à volta do forró. Os atos de execução do ouvir e dançar, em conjunto, são suportes de fluxos e interações e, portanto, geradores de sentido e coesão para o grupo.

Contudo, Forró Valência também é o núcleo de pessoas que se reúnem ao redor de Rodrigo para colaborar no projeto de difusão da cultura do forró. Este grupo é formado por seis pessoas e, à exceção de Rodrigo, os demais são espanhóis, sendo eles dois rapazes e três mulheres. Esse trabalho implica planificar, coordenar e comunicar as ações do grupo, realizadas de forma coletiva e autogerida. Assim, as pessoas que constituem o núcleo Forró Valência realizam o trabalho cooperativo, mobilizando os seus próprios recursos profissionais, econômicos, simbólicos e sociais, sem apoio institucional.

Existe, em Espanha e na Europa, uma rede de professores, músicos e DJs de forró que funciona como uma grande teia de apoios. Nesta rede é possível encontrar posições que vão desde visões principalmente empresariais até perspectivas mais informais. A linha central está na flexibilidade dos requisitos econômicos. Alguns agentes culturais só vão às chamadas que possam garantir benefícios financeiros. Outros, por sua vez, apresentam maior flexibilidade e se adaptam às condições econômicas, sendo que um terceiro grupo movimenta-se entre as duas visões. O trabalho coletivo do grupo Forró Valência gera as condições para mobilizar essa rede de professores e músicos, fazendo circular os símbolos e narrativas do forró.

Uma atividade fundamental do grupo Forró Valência é a organização de festas para criar um senso comunitário. Para isso, se escolheu outro projeto cultural alternativo da cidade, chamado La Chimenea. Este projeto de estilo alternativo, no qual a rentabilidade econômica não é a prioridade, permitiu manter a entrada livre. As festas foram batizadas de "Mogudas Forrozeiras", sendo uma combinação de valenciano, a língua comunitária da Comunidade Valenciana, e português. Trata-se de um exercício de adaptação que está posto como tarefa na construção da identidade local. Nas festas, são convidadas pessoas para que cozinhem e vendam comida brasileira, assim os participantes podem dançar, comer e beber sem precisar de sair do espaço. Essas festas têm uma dupla função: a de captar alunos para as aulas e de satisfazer a necessidade coletiva de se juntar para dançar. As formas de organização estão mais próximas da visão da cultura como direito, promovidas por movimentos como o "Copyleft", ou movimento da Cultura Livre, do que a visão da cultura como serviço promovida pelas indústrias culturais (Rowan 2010). 
Nas festas encontram-se diversos públicos, espanhóis que participam nas aulas semanais do Rodrigo, muitos deles estudantes universitários ou pessoas com emprego e formação superior. Há também um público estrangeiro formado por universitários e residentes em Valência, bem como de brasileiros que não tinham contato prévio com aulas de forró. Neste sentido, o perfil aproxima-se muito do público habitual encontrado em Lisboa, no Centro Cultural Arte Pura.

O consumo musical das festas é dirigido por Rodrigo; nelas se escuta forró tradicional pé-de-serra, embora também se possa ouvir bandas modernas e contemporâneas mais vinculadas ao estilo forró universitário. O controle sonoro sobre o que se escuta não é involuntário e ocorre pela mediação da ação do DJ, neste caso, o próprio Rodrigo, que controla toda a tecnologia de som. Esta exclusão e recorte de escolha do tipo de forró tem também a pretensão de garantir o diálogo corporal com os ritmos e a sensualidade da dança, também presente noutros segmentos do forró, mas sobretudo ensejar a audibilidade e a fidelização de um gosto musical à volta de um dos tipos de forró.

Enfatizamos que, para o grupo, o forró tradicional responde a uma estética definida pelo tipo de instrumentos utilizados: triangulo, zabumba e sanfona - embora se aceitem variações, escutando bandas que põem ou tiram instrumentos deste trio - e pelos estilos rítmicos tradicionais do forró como o baião, o xote, o xaxado e o arrasta-pé. Essa estética tenta defender-se, em oposição ao forró comercial, em que se enfatizam sonoridades dos sintetizadores e não há preocupação por manter a tradição dos ritmos. As festas também comportam arranjos, encenações espaciais e performáticas, que tentam aproximar-se de uma estética visual do Nordeste brasileiro. São utilizadas bandeirolas, como nas festas de São João, e são colocados cartazes com imagens de personagens importantes da cultura do forró, como Luiz Gonzaga, Dominguinhos e Marinês. Também estão expostos chapéus de cangaceiros, como decoração, e há um processo de revisão dos mitos e das figuras da cultura popular nordestina, para fazê-los funcionarem como parte do trabalho de recriação e produção de uma comunidade de forró em Valência.

Esses elementos são parte de uma narrativa da cultura popular como espaço de resistência e criatividade, onde se dá importância e ganham sentido valores como a solidariedade, a alegria ou a familiaridade. A mediação social que se articula mediante o forró em Valência leva-nos a compreendê-la em dois movimentos: por um lado, a ressignificação da posição social do imigrante e a reinvenção da sua comunidade de origem na cidade de recepção; e, por outro, a reconstrução da experiência de comunidade perdida, por parte do público europeu.

O público espanhol em Valência se aproxima do forró pelo ambiente relacional, pelas pessoas. Num primeiro momento, a diferença idiomática e cultural faz com que não exista um atrativo especial pelas letras ou pela compreensão do contexto musical. A melodia é alegre e o ritmo bom de dançar, e isso chega para uma pessoa que vem pela primeira vez a uma festa ou a uma aula de forró. Os integrantes da comunidade que viajam para festivais em outros países comentam que o bom ambiente, a convivência positiva e o espirito de troca do Forró Valência são elementos particulares ao projeto.

Entre as ideias que constituem o imaginário dos que aderem a esse estilo musical, o forró é percepcionado como uma dança que ajuda a desfazer as barreiras sociais, com o contato físico, e condiciona a procura de harmonia. Para a grande maioria dos nossos entrevistados, essa experiência, embora carregada de erotismo, faz parte de uma vivência respeitosa e vivida como um 
contato emocional de não-violência ou ausência de agressividade. Os frequentadores habituais das festas e das aulas do grupo Forró Valência expressam abertamente o seu amor pela dança, por se encontrarem e dançarem juntamente com outras pessoas. A dança, no seu conjunto, é interiorizada como um momento de cura. Este modo de ressignificação da corporeidade e o contato mediante as narrativas rítmicas e físicas dessas expressões sócio-musicais, fazem um contraponto com a capacidade que as nossas sociedades perderam para produzir comunidade, corpo coletivo e vínculos afetivos no contexto europeu. Nesta situação, o forró poderia funcionar como uma prática-ferramenta que permite experimentar a restauração do vínculo, vivido não como um objetivo racional, mas como uma experiência emocional, um vínculo fundado num sentimento comum e compartilhado de bem-estar, felicidade e saúde. Deste ponto de vista, verificamos o que nos disse Lipovetsky e Serroy (2014) sobre o estado atual do capitalismo, em que a cultura é vivida como uma espécie de espiritualidade laica que rege as relações de sociabilidade, mediada pelo consumo de bens culturais.

O Forró Valência tem tido um crescimento rápido na cidade. No prazo de um ano o forró tem passado a ocupar espaços culturais e a ser uma expressão musical reconhecida nos espaços de dança da cidade, conquistando legitimidade cultural associada a ritmos como o Lindy Hop, a Salsa, a Quizomba ou Blues. A partir da difusão pelas redes sociais das festas e da atividade do coletivo, a cidade é vista como um ponto a mais na rede de forró na Europa. Isto significa que muitas bandas de música e professores ofereceram ao grupo, mediante o contato direto com Rodrigo, a possibilidade de vir a Valência para fazer espetáculos ou ministrar oficinas de forró. As consequências desse empreendimento implicaram na melhoria das estratégias para garantir a participação, na procura por lugares adequados para receber esse tipo de evento, realizando um trabalho específico de produção e comunicação audiovisual, fazendo registros fotográficos e de vídeo das aulas e das festas, e na confecção de camisas com a logomarca do Forró Valência.

Essa integração do projeto Forró Valência na rede de forró da Europa, supõe um reconhecimento especial do Rodrigo, como produtor cultural e agente mediador do forró, feita tanto pelos seus pares, os imigrantes brasileiros que compartilham o objetivo de difundir o forró, como por agentes culturais locais que percebem no forró uma prática cultural com capacidade de mobilizar capital social e econômico. Para fazer frente aos encargos financeiros das festas, são feitos arranjos de várias ordens. Os custos dos músicos são negociados em função dos valores das entradas nas festas e os mesmos são convidados a dormir em casa dos membros do grupo organizador, que cooperam como guias turísticos, tradutores e amigos.

Entre os músicos que têm vindo para Valência encontram-se bandas formadas na Europa, como Forró Afiado, Forró Mior, Forró do Dendê, ou DuCaña, e bandas que vêm do Brasil para fazer tour europeu, como o Trio Maracá, Coisa de Zé ou Everton Coroné. Nas bandas que residem na Europa são produzidas colaborações com músicos locais, como na banda Forró Afiado, onde a sanfoneira é espanhola, ou em Forró do Dendê, onde o sanfoneiro é italiano. Também há bandas formadas exclusivamente por músicos não brasileiros, como Forró Mior, na qual as nacionalidades são diversas: Itália, Argentina, Grécia e Angola.

Em agosto de 2016, o coletivo Forró Valência, organizou o evento "I Encuentro de Forró del Mediterráneo". A inclusão do mediterrâneo no nome do evento vincula ideias e imagens próprias do contexto local, como praia, sol, calma, familiaridade e hospitalidade. No mediterrâneo e na brasilidade, há dois mitos facilmente traduzíveis que aproximam narrativas de comunidade e bem-estar. O mediterrâneo é uma imagem de dupla direção, incorpora valores do forró, como 
a comunidade, a alegria e a sensualidade ao público europeu, e ao mesmo tempo traduz um contexto de familiaridade, hospitalidade e bem viver para o público brasileiro.

Por último, vemos como nos workshops também se negoceiam os significados do forró. Os professores que ministram as aulas não só transmitem uma técnica, mas também criam o sentido com o qual o público europeu consome aquela prática. Dentro dos workshops de forró, dirigidos por Átila Alves, professor brasileiro residente em Basileia, dá-se ênfase no abraço, na conexão, na intimidade que, segundo este professor de dança, funciona como ferramenta para recuperar o vínculo com a outra pessoa e aprender a dançar melhor, sem receio do contato físico. São realizados exercícios para melhorar a conexão na intimidade, para melhorar a experiência da dança, para aprender a produzir um vínculo corporal com a outra pessoa, quebrando barreiras corporais. Na compreensão de Átila, o forró é a arte do abraço, não há forró se os pares não dançam colados e é necessário partilhar para esquecer que são duas pessoas e se tornarem uma unidade.

\section{Conclusão}

Os estudos de caso de Lisboa e Valência nos mostram que os fluxos entre os espaços globais podem ocorrer nos mais diferentes formatos. Falamos de duas cidades da Península Ibérica, que se associam, neste estudo, pela sua condição de latinidade e onde a imigração vinda das "ex-colônias" é bastante representativa. Ocorre que, nesses dois locais, experimentações prévias com outros ritmos oriundos das populações migrantes, brasileira e africana em Portugal, e latino-americana na Espanha, foram bem sucedidas. Assim, a Quizomba africana, como a Salsa cubana, fizeram seus caminhos de inserção e aceitação no mercado ibérico, algo próximo do que agora relatamos com o forró. A hipótese de que esta latinidade surge como uma âncora que, em última análise, facilita o processo de internacionalização do forró, é plausível e verificável. Contudo, não é de todo o cerne das explicações, uma vez que, noutros estados europeus, o forró também fez passagem com volumoso êxito. $\mathrm{O}$ que este estudo comparativo nos mostra é que os processos globais se, por um lado, fazem uso de similitudes culturais que aproximam lugares remotos do mercado global, esta não é, apenas, a sua única estratégia.

Os mecanismos de crescimento do forró no Brasil e no mundo fazem-nos questionar: como os grupos subalternos dos meios rurais do Nordeste brasileiro foram capazes de produzir um ritmo musical que ultrapassou o confinamento geográfico regional e tornou-se global, a partir de lógicas próprias inerentes à gênese do forró como gênero musical e de dança?

Entre as possibilidades de resposta a essa pergunta, ressaltamos que no nosso estudo de caso encontramos nos elementos constituintes do forró, na sua relação entre consumo musical e dança, uma resposta possível. O consumo musical surge, nas origens do forró, como relação de convívio e sociabilidade em torno da dança e na trilogia ouvir, dançar e entreter. Este sentido particular é o que confere possibilidades à existência de uma microeconomia afetiva do forró. Quando nos reportamos à microeconomia afetiva, não nos reportamos apenas às relações econômicas de consumo de um produto, mas, principalmente, à gestão das relações afetivas criadas a partir da vivência de consumo de uma prática cultural. 
Essas microeconomias afetivas nos revelam necessidades humanas prementes, como viver em conjunto, sentir em conjunto e dançar, fazendo uso da sensualidade e de mecanismos corporais do afeto. Esses formatos de consumo cultural global sugerem-nos outras necessidades humanas, mais profundas e difíceis de satisfazer que as formas de consumo a que estamos habituados. Em última análise, falamos de uma mercadorização global de formas de sociabilidade e afeto, encontradas, por exemplo, em práticas culturais como o forró que, no seu formato micro, possui desdobramentos peculiares.

Os percursos globais dos bens culturais imateriais, como o forró, sempre seguem lógicas próprias, muito embora as forças propulsoras que os fazem mover se relacionem com as dinâmicas do capitalismo global, movimentos migratórios, redes de interação turísticas ou fluxos das redes digitais. Por trás dessas engrenagens complexas, que designamos genericamente de processos transnacionais e que podem seguir vieses mercadológicos, existem lógicas e subjetividades, pessoas, afetos, modos de estar, estilos de vida, processos decisórios de formas de consumo cultural, sociabilidades e construções de narrativas identitárias, pessoais ou coletivas. Por aí também passa o entendimento dos trajetos transnacionais do forró e a sua microeconomia afetiva no contexto global.

\section{Bibliografia}

Blumer, H.1969. Symbolic Interactionism: Perspective and method. Englewood Clifs, NJ: PrenticeHall.

Bourdieu, Pierre. 2007. A distinção: crítica social do julgamento. São Paulo: Edusp; Porto Alegre. Cruz, D. M. 2012. "Maracatu New York: Transregional Flows Between Pernambuco, New York, and New Orleans". Canadian Journal of Latin American and Caribbean Studies, v. 37, p. 81-108.

Hardt, Michael; Negri, Antônio. 2004. Multitud: Guerra y democracia en la era del Imperio. Barcelona: Debate.

Jenkins, Henry. 2009. Cultura da convergência. 2. ed. São Paulo: Aleph.

Lipovetsky, Gilles; Serroy, Jean. 2014. O capitalismo estético na era da globalização, Lisboa: Edições 70.

Marcus, George. 1995. "Ethnography in/of the World System: The Emergence of Multi-Sited Ethnography”, Annual Review of Anthropology. Palo Alto, California, 24: 95-117.

Nascimento, Ricardo César Carvalho. 2015. "Mandinga for export: a globalização da capoeira na Europa”. Tese de Doutoramento em Antropologia. Universidade Nova de Lisboa.

Rowan, Jaron. 2010. Emprendizajes en cultura. Discursos, instituciones y contradicciones en la empresarialidad cultural. Madrid: Traficantes de sueños.

Sarquis, Joana. 2013. "Forró sem fronteiras - o movimento em Portugal". Dissertação de Mestrado. Universidade Técnica de Lisboa.

Silva, E. L. 2003. Forró no Asfalto - Mercado e Identidade Sociocultural. São Paulo: Annablume. Simmel, George. 2013. O conflito da cultura moderna e outros escritos. São Paulo: Editora SENAC. Tinhorão, José Ramos. 1998. História social da música popular brasileira. São Paulo: Editora 34. Trotta, Felipe; Monteiro, Márcio. 2008. "O novo mainstream da música regional: axé, brega, reggae e forró eletrônico no Nordeste”. E-compós, Revista da associação nacional dos programas de pós-graduação em comunicação. Brasília, V. 11, n. 2. 


\section{Affective And global micro-economies of forró in the Iberian Peninsula}

Forró is a musical and performative genre, coming from rural areas in the north-eastern region of Brazil, which today is widespread in the form of dance and music throughout the world. The global contours of its growth involve a particular cultural and affective economy within which commercial and non-commercial circuits intertwine in relations of sociability, leisure and well-being. The purpose of this article is to understand the intricacies of the process of trans-nationalisation of forro, its economic, cultural and sociability dynamics, based on a case study and a multi-situated ethnography, with forró practitioners in the cities of Lisbon, Portugal, and Valencia, Spain.

Keywords: cultural economy, globalization, forró, sociability

Recebido em: 2017-05-31

Aceitado em: 2012-02-24 